He might have added that the simplest of experiments would suffice to disprove them, as Clerselier clearly pointed out. It is therefore no injustice to Descartes to declare, as did Whewell in the History of the Inductive Sciences, that "if we were to compare Descartes with Galileo, we might say that of the mechanical truths which were easily obtainable at the beginning of the seventeenth century, Galileo took hold of as many, and Descartes as few as was well possible for a man of genius".

Chapter 6, on order of composition and dating of manuscripts, is particularly valuable inasmuch as we learn from it the extent to which Newton was treading on virgin soil, and, here again, Mr. Herivel has placed us heavily in his debt. Newton, like so many of his contemporaries, was often careless as to dates, and in giving a procise chronology of the steps leading to the publication of the Principia, Mr. Herivel has rendered a very useful service.

One of the most valuable features of this work is the comprehensive index which has been supplied, and this the reader will find most helpful. If, and when, a second edition of this work is planned, Mr. Herivel might consider the provision, in an appendix, of brief biographical notes on some of the lessor known persons mentioned in its pages. Not every reader is familiar with the contributions of such men as Borelli, Bradwardine, Gassendi or Paget, to name but a few.

The Background to Newton's Principia is a work which should have a place on the bookshelves of all who are interested in the history of science during the illustrious seventeenth century.

J. F. Sсотт

\section{LECTURES ON MOLECULAR SPECTROSCOPY}

\section{Molecular Spectroscopy-VIII}

(Invited Lectures presented at the VIIIth European Congress on Molecular Spectroscopy, held in Copenhagen, Denmark, August 14-20, 1965.) (Pure and Applied Chemistry, Vol. 11, Nos. 3-4, 1965.) Pp. vi $+261-582$. (London: Butterworth and Co. (Publishers), Ltd., 1966.) 758 .

THE organizers of the eighth European Congress on Molecular Spectroscopy at Copenhagen have been wise in restricting the publication to the invited papers presented at this meeting. They represent useful summaries or reviews of various topics, and any objections to the publication of conference proceedings in general do not apply to the present volume. The meeting in Copenhagen was a very large meeting with about 800 participants and many parallel sessions were necessary. Consequently, it was not possible for an individual participant to attend all the invited lectures, and it is very useful to have all (or almost all) the invited lectures collected together in one volume. The meeting in Copenhagen may have been the last meeting to cover the whole of molecular spectroscopy. Correspondingly, the present volume deals with a large varicty of topics, several of them extremely well presented.

Many of those who attended the meeting will remember the beautiful opening lecture of Professor Daudel on the role of wave mechanies in the interpretation of molecular spectra. It is a fine summary which elearly brings out the constant dialogue between theory and experiment in the development of both the detailed theory of small molecules and the semi-empirical theory of large molecules. There are several other invited theoretical lectures, in which I. M. Mills considers the effect of Coriolis interactions on rotation-vibration spectra and is able to present examples which show the possibility of obtaining information about the potential functions from the effects of Coriolis interactions; $H$. Preuss deals with the potential functions of polyatomic systems; ( G. J. Hoijtink deals with triplet-triplet spectra of alternant hydrocarbon molecules; J. T. Hougen gives a thorough discussion of the vibrations in molecules with nearly free internal rotations; and I. Fischer-Hjalmars presents a theoretical study of systems with heteroatoms.

In addition to these theoretical papers, there are a number of excellent papers on experimental subjects. Many will remember the very fine lecture by Mössbauer, who showed how the effect bearing his name can be applied to problems of electronic shielding in the rare earths. This paper deals, in other words, with the spectroscopy of very small wavelengths, that is, gamma radia. tion. There is very little discussion of the vacuum ultra. violet region or of spectra of diatomic molecules, at least in the invited papers, but the visible and near ultra-violet spectra of polyatomic molecules are well represented. Th. Förster deals with the polarization of the photoluminescence in solutions. M. Kasha deals with the exciton model and its use in the interpretation of the spectra of aromatic molecules, and $H$. Kuhn reports on very interesting experiments in which simple organized systems of molecules are built up and their absorption and fluor. escence are investigated as a preparation for an understanding of biological structures.

A very stimulating paper is presented by $B$. P. Stoicheff on molecular spectroscopy with optical masers. Apart from giving a very useful summary of the prosent status of this field, he reports his recent discovery of the inverse Raman effect.

In line with the historical development of the European molecular spectroscopy meetings, a good deal of emphasis remains with vibrational spectroscopy. (The ninth meeting in Madrid next September is to be devoted entirely to this subject.) D. Hadzi reports on the infra-red spectra of strongly hydrogen-bonded systems, while L. A. Woodward discusses the Raman spectra of aqueous solutions, and D. O. Hummel describes the infra-red spectra of macromolecules. One of the most interesting developments reported at this meeting is the first success in obtaining infra-red spectra of free radicals produced by flash photolysis. This work is described by G. C. Pimentel in his invited lecture and at the meeting it was also discussed by R. M. Hexter in one of the contributed papers (not included in this volume).

Microwave spectroscopy is represented by the lectures of two of the pioneers in this field. W. Gordy reports on the extension of microwave spectroscopy into the submillimetre region, while J. Sheridan discusses some recent results and future trends in microwave spectroscopy.

Only one of the invited papers, that of R. A. Hoffman, deals with nuclear magnetic resonance spectra; in particular, with the analysis of high resolution spectra of this type. Finally, there are two important papers on spectroscopic technique. H. A. Gebbie describes the important developments in the field of interference spectroscopy to which he himself has made such fine contributions, and P. L. Richards describes the latest developments in infra-red detectors.

All in all, this volume represents a very useful summary by competent authors of some of the most important topics in spectroscopy. The book is well printed, and, in particular, the half-tone reproductions are well done. The lectures are published in the original language of the particular authors although the actual presentation of most of the lectures was in English. G. HerzBERG

\section{BROMINE HANDBOOK}

\section{Bromine and Its Compounds}

Edited by Z. E. Jolles. Pp. xxvii +940. (London: Frnost Benn, Ltd., 1966.) 210s. net.

THIs book deals with almost every conceivable aspect of the chemistry of bromine and its compounds. There 